\title{
RANCANG BANGUN SISTEM INFORMASI JUDUL DAN PEMBIMBING SKRIPSI /TUGAS AKHIR FKOM UNIKU
}

\author{
Rio Andriyat Krisdiawan ${ }^{1}$ \\ 1), Teknik Informatika Universitas Kuningan \\ Jl Cut Nyak Dien No 36 A Cijoho Kabupaten Kuningan \\ Email : rioandriyat@uniku.ac.id ${ }^{l)}$
}

\begin{abstract}
Abstrak
Fakultas Ilmu Komputer adalah salah satu fakultas yang terdapat di Universitas Kuningan. Fakultas tersebut memiliki 4 Program studi yaitu Teknik Informatika S1, Sistem Informasi S1, Manajement informatika D3, dan Teknik Informatika D3. Dalam proses mencetak lulusan-lulusan di bidang computer yang unggul, mahasiswa harus dapat menentukan ide yang sesuai dengan perkembangan teknologi dan kebermanfaatan yang luas untuk diajukan dalam judul skripsi dan tugas akhir. Begitu juga dalam proses penentuan pembimbing skripsi yang sesuai dengan kompetensi dari judul yang diajukan harus sesuai dengan kompetensi dosen yang dipilih sebagai dosen pembimbing. Dari proses pengajuan judul, dan pengajuan dosen pembimbing yang dilakukan oleh mahasiswa, memerlukan pelayanan informasi yang terupdate dari Program studi dan Fakultas Ilmu Komputer, sebagai salah satu pelayanan agar mahasiswa tersebut mudah dalam menentukan judul dan menentukan pembimbing skripsi/tugas akhir. Sistem informasi yang akan Perancangan aplikasi di buat dengan metodologi pengembangan sistem RUP (Rational Unified Process). Aplikasi yang akan dibuat menggunakan bahasa pemrograman berbasis WEB dengan bahasa pemrograman $P H P$ dan database $M y S Q L$.
\end{abstract}

Kata Kunci : FKOM UNIKU, Pembimbing Skripsi/Tugas Akhir, RUP, PHP dan MySQL.

Abstract

Faculty of Computer Science is one of the faculty located at the University of Kuningan. The faculty has 4 study programs, namely Informatics Engineering S1, S1 Information System, D3 Informatics Management, and Informatics Engineering D3. In the process of printing graduates in the field of computer excellence, students must be able to determine the idea in accordance with technological developments and wide usefulness to be submitted in the title of thesis and final project. Likewise in the process of determining mentors thesis in accordance with the competence of the proposed title must be in accordance with the competence of lecturers selected as supervisors. From the process of submission of the title, and the submission of a lecturer supervisor conducted by the students, require updated information service from the Study Program and Faculty of Computer Science, as one of the services so that the student is easy in determining the title and determine the thesis / final supervisor. The information system that will Design the application is made with system development methodology RUP (Rational Unified Process). The application will be created using WEB-based programming language with PHP programming language and MySQL database.

Keywords: FKOM UNIKU, Supervising Thesis / Final Task, RUP, PHP and MySQL.

\section{PENDAHULUAN}

Fakultas Ilmu Komputer adalah salah satu fakultas yang terdapat di Universitas Kuningan. Fakultas tersebut memiliki 4 Program studi yaitu Teknik Informatika S1, Sistem Informasi S1, Manajement informatika D3, dan Teknik Informatika D3. Dalam proses mencetak lulusanlulusan di bidang computer yang unggul, mahasiswa harus dapat menentukan ide yang sesuai dengan perkembangan teknologi dan kebermanfaatan yang luas untuk diajukan dalam judul skripsi dan tugas akhir. Begitu juga dalam proses penentuan pembimbing skripsi yang sesuai dengan kompetensi dari judul yang diajukan harus sesuai dengan kompetensi dosen yang dipilih sebagai dosen pembimbing.

Dari proses pengajuan judul, dan pengajuan dosen pembimbing yang dilakukan oleh mahasiswa, memerlukan pelayanan informasi yang terupdate dari Program studi dan Fakultas Ilmu Komputer, sebagai salah satu pelayanan agar mahasiswa tersebut mudah dalam menentukan judul dan menentukan pembimbing skripsi/tugas akhir. Sistem informasi yang akan Perancangan 
aplikasi di buat dengan metodologi pengembangan sistem RUP (Rational Unified Process).

Aplikasi yang akan dibuat menggunakan bahasa pemrograman berbasis WEB dengan bahasa pemrograman $P H P$ dan database $M y S Q L$

Peneliti merancang sebuah system informasi pembimbing dan judul skripsi/tugas akhir berbasis web yang dapat diakses oleh semua civitas akademik di Fakultas Ilmu Komputer dengan judul

"Rancang Bangun Sistem Informasi Judul dan Pembimbing Skripsi/Tugas Akhir FKOM UNIKU".

Rumusan permasalahan dalam penelitian ini:

1. Bagaimana merancang sebuah system informasi judul, pembimbing skripsi/tugas akhir yang dapat diakses oleh semua civitas akademik di Fakultas Ilmu Komputer.

2. Bagaimana mengelola jumlah mahasiswa bimbingan berdasarkan dosen pembimbing yang ada di Fakultas Ilmu Komputer.

3. Bagaimana membangun system yang dapat mengelola judul-judul skripsi yang diajukan oleh mahasiswa untuk memaksimalkan kesesuaian kompetensi dengan program studi di Fakultas Ilmu Komputer

Untuk memfokuskan agar tidak meluas maka penulis membatasi permasalahan sebagai berikut:

1. Perancangan aplikasi di buat dengan metodologi pengembangan sistem RUP ((Rational Unified Process).

2. Sistem informasi yang akan dibangun mencakup
a. Pengelolaan Judul Skripsi
b. Pengelolaan jumlah maksimal mahasiswa bimbingan berdasarkan dosen pembimbing.
c. Pengelolaan kompetensi dosen pembimbing berdasarkan program studi.

3. Aplikasi yang akan dibuat menggunakan bahasa pemrograman berbasis WEB dengan bahasa pemrograman PHP dan database MySQL.

4. Penelitian ini dilakukan dengan studi kasus di Fakultas Ilmu Komputer Universitas Kuningan.

5. Sistem informasi yang akan dibangun hanya mencakup informasi judul, jumlah mahasiswa bimbingan, serta kompetensi dosen pembimbing.

Maksud dan Tujuan dari penelitian ini adalah sebagai berikut :

Maksud dari penelitian ini adalah sebagai berikut :

1. Sebagai sarana pelayanan informasi untuk semua civitas akademik di lingkungan Fakultas Ilmu Komputer.

2. Untuk mengetahui jumlah pengajuan judul dan pembimbing skripsi/tugas akhir.

3. Sebagai media pengarsipan data judul skripsi mahasiswa di fakultas ilmu komputer universitas kuningan.
Adapun Tujuan dari penelitian ini adalah sebagai berikut:

1. Mempermudah mahasiswa dalam mengajukan judul dan dosen pembimbing skripsi/tugas akhir

2. Membuat sebuah system informasi pengelolaan judul dan pembimbing skripsi/tugas akhir di Fakultas Ilmu Komputer.

3. Untuk menganalisa, merancang, dan mengimplementasikan perkembangan teknologi dalam pelayanan informasi judul dan pembimbing skripsi/tugas akhir.

\section{Pengertian Skripsi}

Menurut Pedoman Penyusunan Skripsi \& Tugas Akhir Fkom Uniku 2011

"Skripsi adalah karya tulis ilmiah resmi akhir seorang mahasiswa dalam menyelesaikan Program Sarjana (S1). Skripsi merupakan bukti kemampuan akademik mahasiwa dalam penelitian yang berhubungan dengan bidang keahliannya. Skripsi disusun dengan bimbingan 2 (dua) orang dosen pembimbing dan dipertahankan dalam ujian sidang untuk mencapai gelar Sarjana.

Tugas Akhir adalah karya tulis ilmiah resmi akhir seorang mahasiswa dalam menyelesaikan Program Diploma (D3). Tugas Akhir merupakan bukti kemampuan akademik mahasiwa dalam penelitian yang berhubungan dengan bidang keahliannya. Tugas Akhir disusun dengan bimbingan 1 (satu) orang dosen pembimbing dan dipertahankan dalam ujian sidang untuk mencapai gelar Ahli Madya."

Sedangkan menurut Kamus Besar Bahasa Indonesia (KBBI) "Skripsi adalah karangan ilmiah yang wajib ditulis oleh mahasiswa sebagai bagian dari persyaratan akhir pendidikan akademisnya".

\section{Pengertian Aplikasi Berbasi WEB}

Menurut (Kadir, 2009, p. 2) “Aplikasi Web adalah jenis aplikasi yang diakses melalui browser, misalnya Internet Explorer dan Mozila Firefox."

Menurut makalah Arif Rifai (2009:1), Pengertian aplikasi berbasis web adalah :

"Aplikasi sisi server (server side) yang menggunakan standar HTTP dan menggunakan browser untuk menggunakan aplikasi. Termasuk didalamnya teknologi PHP, ASP dan lainnya".

Berdasarkan sumber internet dengan alamat www.utexas.edu, Aplikasi berbasis web dibangun diatas HTTP. HTTP merupakan salah satu protokol yang berjalan diatas TCP/IP (protokol internet). HTTP adalah protokol yang stateless, web server hanya memberikan informasi yang diminta, setelah itu koneksi diputus.

Menurut Soetam Rizky, ada beberapa keunggulan aplikasi berbasis web, diantaranya : 
1. Aplikasi yang langsung dapat dijalankan melalui browser.

2. Bisa dengan koneksi internet, intranet maupun stand alone.

3. Defice dan system operasi tidak terbatas.

4. Terjadi umpan balik antara pengguna dan server penyedia, tidak statis.

5. Jenis bahasa pemrograman tidak berpengaruh terhadap hasil aplikasi.

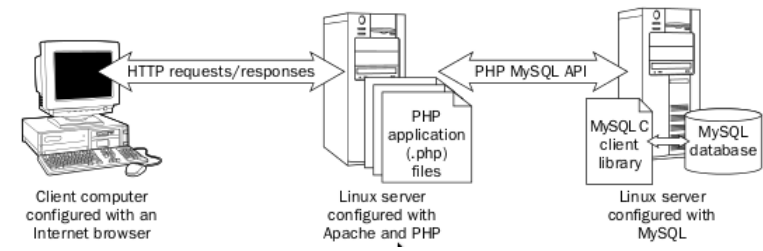

Gambarl struktur Aplikasi berbasis web

\section{METODE PENELITIAN}

Metodologi Berorientasi Objek

Objek juga didefinisikan sebagai berikut:

"objek dapat didefinisikan sebagai suatu encapsulation atau penggabungan dari data (yang diwakilkan oleh atribut-atribut) dan operasioperasi (disebut juga metode/prosedur) yang akan melakukan proses terhadap data-data tersebut."

\section{Keuntungan Metodologi Berorientasi Objek}

Keunggulan metoda berarah objek diantaranya adalah (Coad and Yourdon, 1991):

1. Meningkatkan produktifitas

Karena kelas dan objek yang ditemukan pada suatu kasus masih dapat dipakai ulang untuk kasus lainnya yang melibatkan objek tersebut(reusable);

2. Meningkatkan kualitas

Karena sistem yang dibangun dengan baik dan benar pada saat analisis dan perancangannya akan menyebabkan kekurangannya kesalahan pada saat pengkodean,

3. Mempermudah perawatan

Karena dengan model objek pola-pola yang cenderung tetap dan stabil dapat dipisahkan dari pola-pola yang mungkin sering berubah-ubah,

4. Adanya konsistensi

Karena sifat pewarisan dan penggunaan notasi yang sama pada saat analisis, perancangan, maupun pengkodean.

\section{Unified Modelling Language (UML)}

Unified Modelling Language (UML) adalah keluarga notasi grafis yang didukung oleh modelmodel tunggal, yang membantu pendeskripsian dan desain sistem perangkat lunak, khususnya sistem yang dibangun menggunakan pemrograman berorientasi objek.(Martin Fowler,2004).

Dengan menggunakan $U M L$ kita dapat membuat model untuk semua jenis aplikasi piranti lunak, dimana aplikasi tersebut dapat berjalan pada piranti keras, sistem operasi dan jaringan apapun, serta ditulis dalam bahasa pemrograman apapun. Tetapi karena UML juga menggunakan class dan operation dalam konsep dasarnya, maka ia lebih cocok untuk penulisan piranti lunak dalam bahasabahasa berorientasi objek seperti $\mathrm{C}++$, Java, C\# atau VB.NET. Walaupun demikian, $U M L$ tetap dapat digunakan untuk modeling aplikasi prosedural dalam VB atau C.

\section{Metode Pengembangan Sistem}

Metodologi penelitian yang digunakan yakni tahapan-tahapan yang akan dilakukan dalam proses penyelesaian penelitian dalam rangka untuk memudahkan memecahkan masalah dari awal perencanaan strategis hingga tercapainya tujuan.

Metodologi yang digunakan oleh penulis dalam melakukan penelitian ini adalah RUP (Rational Unified Process). Rational Unified Process merupakan suatu metode rekayasa perangkat lunak yang dikembangkan dengan mengumpulkan berbagai best practises yang terdapat dalam industri pengembangan perangkat lunak. Ciri utama metode ini adalah menggunakan use-case driven dan pendekatan iteratif untuk siklus pengembangan perankat lunak.

Menurut Pressman, "System engineering is a modeling process", yang berarti didalam rekayasa perangkat lunak tidak dapat dilepaskan dari pemodelan proses. Model dapat berupa tiruan dari suatu benda, sistem, atau peristiwa sesungguhnya yang hanya mengandung informasi yang dipandang penting. Kegiatan memodelkan suatu sistem menjadi suatu model yang dapat merepresentasikan sistem tersebut dinamakan pemodelan

Keunggulan metoda berarah objek diantaranya adalah (Coad and Yourdon, 1991):

1. Meningkatkan produktifitas

Karena kelas dan objek yang ditemukan pada suatu kasus masih dapat dipakai ulang untuk kasus lainnya yang melibatkan objek tersebut(reusable);

2. Meningkatkan kualitas

Karena sistem yang dibangun dengan baik dan benar pada saat analisis dan perancangannya akan menyebabkan kekurangannya kesalahan pada saat pengkodean,

3. Mempermudah perawatan

Karena dengan model objek pola-pola yang cenderung tetap dan stabil dapat dipisahkan dari pola-pola yang mungkin sering berubah-ubah,

4. Adanya konsistensi

Karena sifat pewarisan dan penggunaan notasi yang sama pada saat analisis, perancangan, maupun pengkodean

RUP menggunakan konsep object oriented, dengan 
aktifitas yang berfokus pada pengembangan model dengan menggunakan Unified Model Language (UML). Melalui gambar 3.1 dapat dilihat bahwa RUP memiliki 2 dimensi pengembangan, yaitu:

1. Dimensi pertama digambarkan secara horizontal. Dimensi ini mewakili aspek-aspek dinamis dari pengembangan perangkat lunak. Aspek ini dijabarkan dalam tahapan pengembangan atau fase. Setiap fase akan memiliki suatu major milestone yang menandakan akhir dari awal dari phase selanjutnya. Setiap phase dapat berdiri dari satu beberapa iterasi. Dimensi ini terdiri atas Inception, Elaboration, Construction, dan Transition.

2. Dimensi kedua digambarkan secara vertikal. Dimensi ini mewakili aspek-aspek statis dari proses pengembangan perangkat lunak yang dikelompokkan ke dalam beberapa disiplin. Proses pengembangan perangkat lunak yang dijelaskan kedalam beberapa disiplin terdiri dari empat elemen penting, yakni who is doing, what, how dan when. Dimensi ini terdiri atas; Business Modeling, Requirement, Analysis and Design, Implementation, Test, Deployment, Configuration dan Change Manegement, Project Management, Environtment.

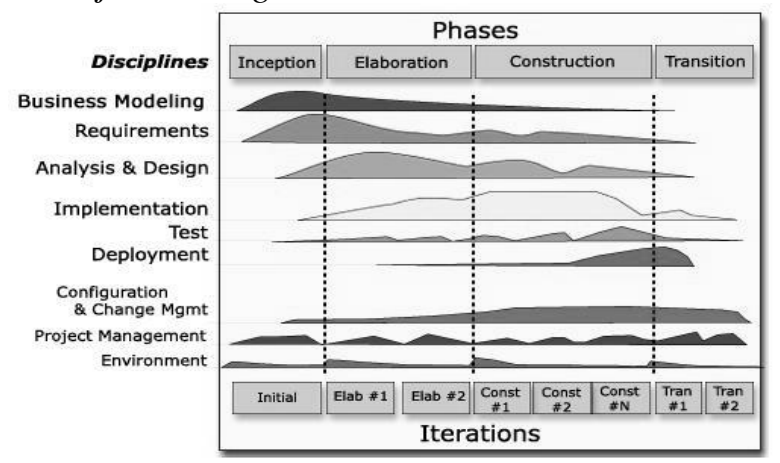

Gambar 2. Gambar Fase RUP

Gambar 2 menjelaskan 4 tahapan yang ada dalam metode RUP. Tahap- tahap dari metode RUP tersebut dapat diuraikan sebagai berikut:

\section{Tahap Inception}

Tahap inception adalah tahapan yang fokus pada penentuan manfaat aplikasi perangkat lunak yang harus dihasilkan. Dalam tahapan inception dari metode RUP langkah-langkah yang dikerjakan adalah sebagai berikut.

a. Mendefinisikan batasan kegiatan.

b. Melakukan analisis kebutuhan user.

c. Melakukan proses perancangan awal perangkat lunak (perancangan arsitektural).
Tahap elaboration adalah tahapan yang digunakan untuk menentukan use case(set of activities) dari perangkat lunak berikut rancangan arsitekturnya. Dalam tahapan elaboration dari metode RUP langkah-langkah yang dikerjakan adalah sebagai berikut.

a. Menspesifikasikan fitur perangkat lunak.

b. Menentukan use case.

c. Membuat prototipe perangkat lunak.

3. Tahap Construction

Tahap construction berisi tahapan pengimplementasian rancangan aplikasi perangkat lunak yang telah dibuat lengkap dan siap diserahkan kepada pemakai. Dalam tahapan construction dari metode RUP langkah-langkah yang dikerjakan adalah sebagai berikut.

a. Perkembangan sistem.

b. Melakukan sederetan iterasi. Proses yang terjadi pada setiap iterasi adalah analisa desain, implementasi dan testing.

c. Merilis aplikasi perangkat lunak berserta dengan dokumentasinya.

4. Tahap Transition

Tahap transition adalah tahapan untuk menyediakan sistem untuk digunakan oleh pemakai. Dalam tahapan transition dari metode RUP langkah-langkah yang dikerjakan adalah sebagai berikut.

a. Menyerahkan aplikasi perangkat lunak kepada pemakai.

b. Melakukan instalasi, pengujian di tempat pemakai.

c. Memperbaiki masalah-masalah yang muncul pada saat dan setelah pengujian

\section{HASIL DAN PEMBAHASAN}

\section{Perancangan Aplikasi}

Pada tahap perancangan sistem informasi bimbingan mahasiswa dengan dosen pembimbing akademik berbasis web ini, dibangun menggunakan UML (Unified Modelling Language). UML adalah bahasa standar yang digunakan untuk menjelaskan dan memvisualisasikan rancangan proses analisis dan desain berorientasi objek

\section{Perancangan Use Case Diagram}

Use Case Diagram mendeskripsikan sistem/aplikasi, lingkungan dan relasi antara sistem/aplikasi dengan lingkungannya. Dalam aplikasi yang dibuat, user memiliki beberapa perlakuan umum yang dapat dilakukan.

\section{Tahap Elaboration}




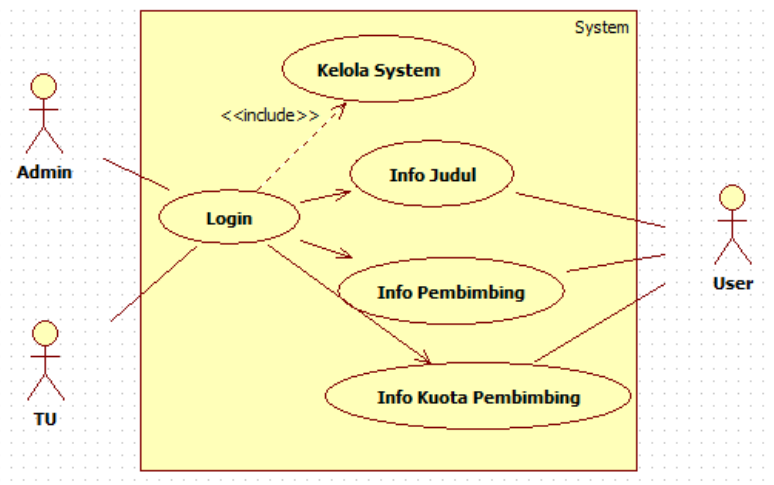

Gambar 3 Use case diagram

Skenario Use Case Login Kep.TU

Tabel 1. Skenario Use Case Login Kep.TU

\begin{tabular}{|c|c|c|}
\hline $\begin{array}{l}\text { Nama } \\
\text { Use Case }\end{array}$ & \multicolumn{2}{|c|}{ Login Tata Usaha } \\
\hline Aktor & \multicolumn{2}{|l|}{ TU } \\
\hline Deskripsi & \multicolumn{2}{|c|}{$\begin{array}{l}\text { Proses Ini adalah sebuah kegiatan } \\
\text { untuk masuk ke dalam sistem } \\
\text { informasi judul dan pembimbing } \\
\text { skripsi/Tugas Akhir. }\end{array}$} \\
\hline \multirow{2}{*}{$\begin{array}{l}\text { Kondisi } \\
\text { Normal }\end{array}$} & TU & Reaksi Sistem \\
\hline & $\begin{array}{l}\text { 1.TU } \\
\text { mengis } \\
\text { i } \\
\text { userna } \\
\text { me dan } \\
\text { passw } \\
\text { ord. }\end{array}$ & $\begin{array}{l}\text { 1. Mengecek valid atau } \\
\text { tidaknya data } \\
\text { masukkan. } \\
\text { 2. Jika Data Masukkan } \\
\text { valid maka akan } \\
\text { menampilkan sistem } \\
\text { utama. }\end{array}$ \\
\hline \multirow{2}{*}{$\begin{array}{l}\text { Kondisi } \\
\text { Alternatif }\end{array}$} & TU & Reaksi Sistem \\
\hline & $\begin{array}{l}\text { 1. TU } \\
\text { mengi } \\
\text { si } \\
\text { userna } \\
\text { me } \\
\text { dan } \\
\text { passw } \\
\text { ord. }\end{array}$ & $\begin{array}{l}\text { 2. Mengecek valid atau } \\
\text { tidaknya data } \\
\text { masukkan. } \\
\text { 3. Jika data masukkan } \\
\text { salah, maka akan } \\
\text { memberitahu pesan } \\
\text { peringatan. }\end{array}$ \\
\hline $\begin{array}{l}\text { Pre- } \\
\text { Condition }\end{array}$ & \multicolumn{2}{|c|}{ TU akan melakukan Login } \\
\hline $\begin{array}{l}\text { Post- } \\
\text { Condition }\end{array}$ & \multicolumn{2}{|c|}{$\begin{array}{l}\text { TU mengisi username dan password } \\
\text { untuk masuk ke sistem. }\end{array}$} \\
\hline
\end{tabular}

\section{Perancangan Activity Diagram}

Activity Diagram merupakan gambaran aliran kejadian suatu aplikasi. Pada activity diagram ini menggambarkan proses yang berjalan di sistem yang dilakukan oleh pengguna dari awal membuka aplikasi sampai menutup aplikasi. Berikut ini adalah gambaran activity diagram ::
Activity diagram input data pembimbing

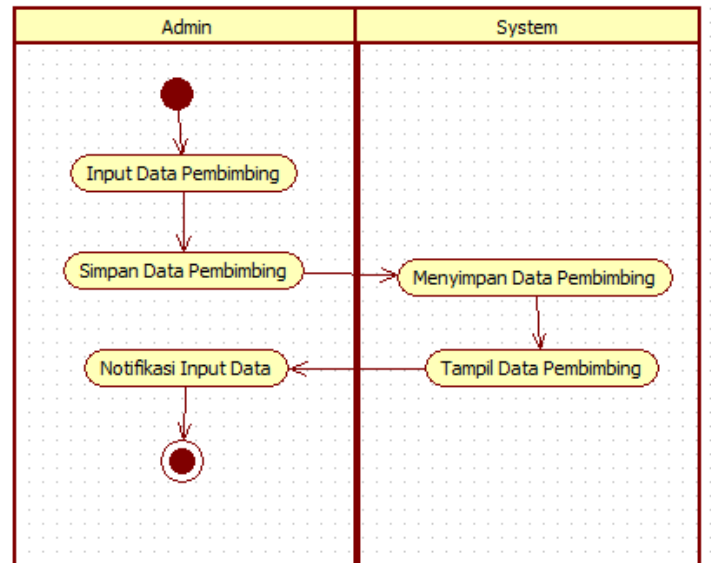

Gambar 4. Activity diagram input data pembimbing Dari activity diagram diatas, maka identifikasi proses yang terjadi diuraikan pada table berikut:

Tabel 2. Deskripsi activity diagram input data

\begin{tabular}{|c|l|l|}
\multicolumn{2}{|c|}{ pembimbing } \\
\hline No & Swimline & \multicolumn{1}{c|}{ Identifikasi Proses } \\
\hline 1 & Admin & $\begin{array}{l}\text { 1. Mengisi data pembimbing } \\
\text { berdasarkan Program Studi } \\
\text { dan Kompetensi }\end{array}$ \\
& & $\begin{array}{l}\text { 2. Klik tombol simpan data } \\
\text { Pembimbing } \\
\text { 3enerima notifikasi input } \\
\text { data Pembimbing }\end{array}$ \\
\hline 2 & Sistem & $\begin{array}{l}\text { 1. Menyimpan data } \\
\text { Pembimbing }\end{array}$ \\
& & $\begin{array}{l}\text { 2. Menampilkan data } \\
\text { Pembimbing hasil input }\end{array}$ \\
\hline
\end{tabular}

\section{Perancangan Class Diagram}

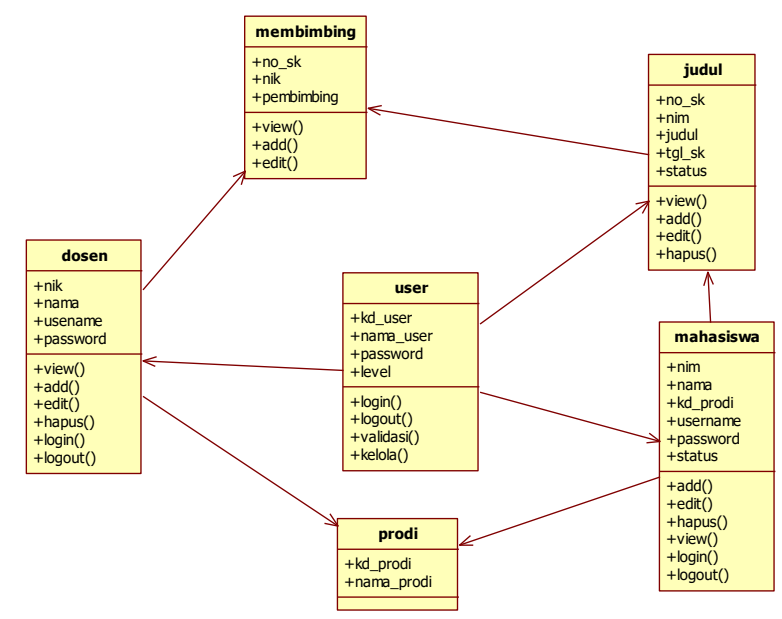

Gambar 5. Class diagram

\section{Perancangan Sequence Diagram}

Perancangan ini akan menampilkan aksi maupun reaksi yang didapat akibat interaksi yang diberikan.

Sequence Diagram info judul dan pembimbing 


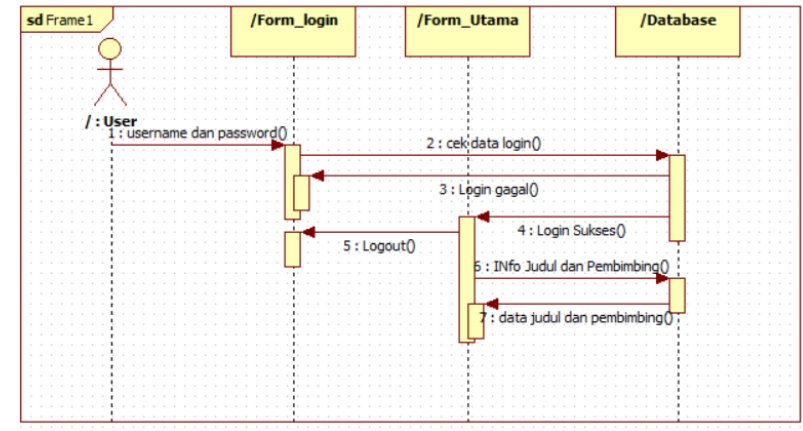

Gambar 6. Sequence diagram info judul dan pembimbing

\section{Construction}

Setelah mengalami sederetan proses iterasi, pada tahapan Construction ini sudah dapat menghasilkan suatu aplikasi. Hasil dari aplikasi yang sudah dirancang dapat dilihat pada tampilan Gambar berikut :

\section{Halaman Utama Aplikasi}

Halaman utama aplikasi ini adalah halaman utama login aplikasi yang diakses oleh semua user untuk masuk kedalam aplikasi tersebut. Dapat dilihat seperti gambar dibawah ini :

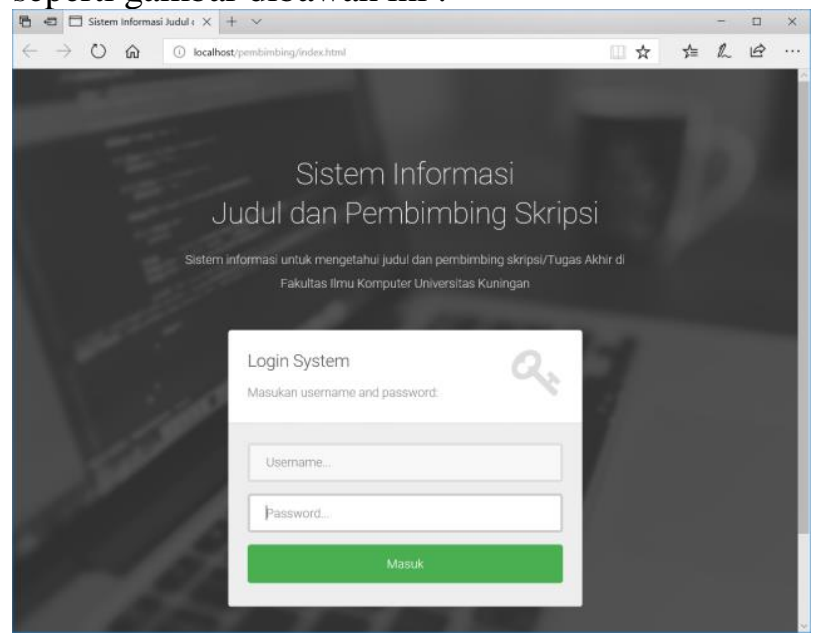

Gambar 7. Halaman Utama Login Aplikasi

\section{Halaman Utama Kepala TU}

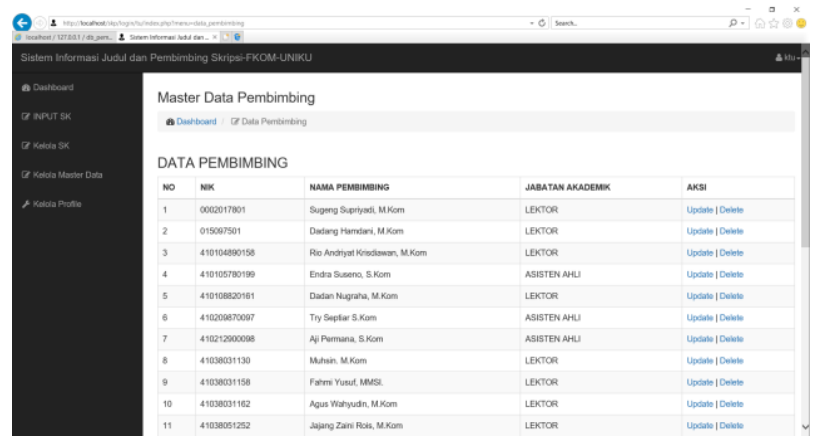

Gambar 8. Halaman Utama Kepala TU
Halaman Laporan SK Judul

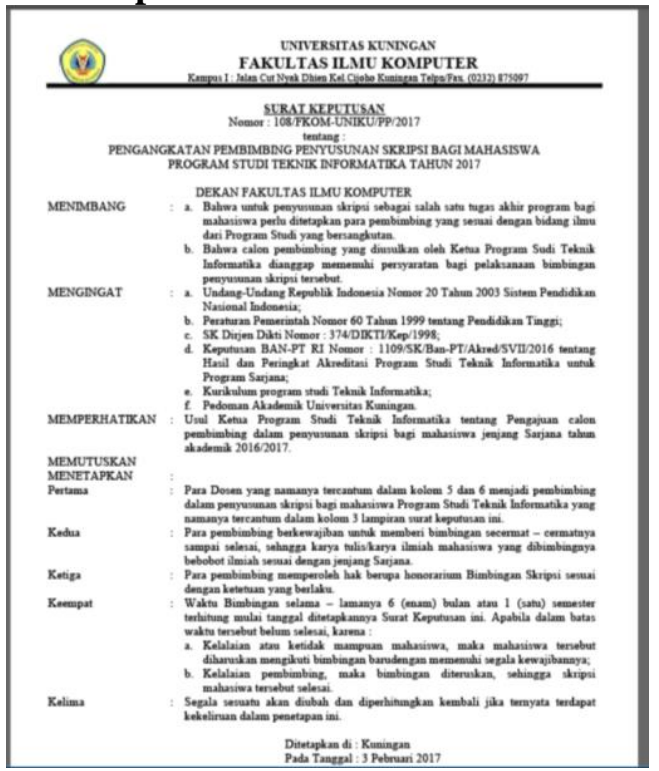

Gambar 9. Laporan SK judul dan Pembimbing Skripsi

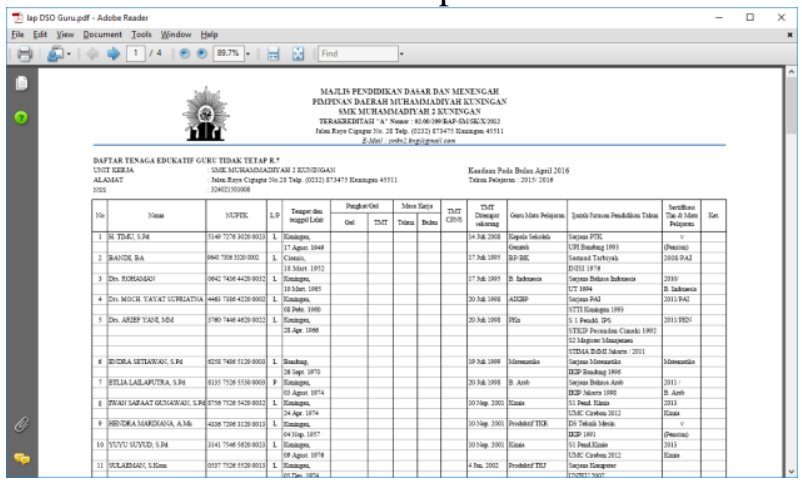

Gambar 10. Gambar Rekap DSO Guru persemester

\section{Transition}

Tahap Transition merupakan tahapan akhir dari proses RUP. Dalam tahapan ini lebih difokuskan pada masalah pengujian. Proses pengujian sendiri memiliki banyak jenis. Proses pengujian adalah proses mengeksekusi aplikasi untuk menentukan apakah apliaksi perangkat lunak tersebut cocok dengan spesifikasi sistem dan berjalan sesuai dengan lingkungan yang diinginkan.

\section{Pengujian Black Box}

Adapun hasil pengujian black box yang telah dilakukan pada Form Menu dapat dilihat pada Tabel 4.1.

Tabel 3..Hasil Pengujian Black Box

\begin{tabular}{|c|l|l|l|l|}
\hline No & $\begin{array}{l}\text { Fungsi } \\
\text { yang di } \\
\text { uji }\end{array}$ & $\begin{array}{l}\text { Cara } \\
\text { Menguji }\end{array}$ & $\begin{array}{l}\text { Hasil yang } \\
\text { diharapkan }\end{array}$ & $\begin{array}{l}\text { Hasil } \\
\text { yang } \\
\text { keluar }\end{array}$ \\
\hline 1 & $\begin{array}{l}\text { Cek } \\
\text { login }\end{array}$ & $\begin{array}{l}\text { Kepala TU, } \\
\text { kepala } \\
\text { sekolah dan } \\
\text { guru } \\
\text { melakukan } \\
\text { login ke }\end{array}$ & $\begin{array}{l}\text { Tamil } \\
\text { Utama } \\
\text { sesuai } \\
\text { dengan user }\end{array}$ & $\begin{array}{l}\text { Sesuai } \\
\text { dengan } \\
\text { harapan } \\
\text { Valid }\end{array}$ \\
& & \multicolumn{3}{|l}{} \\
\hline
\end{tabular}




\begin{tabular}{|c|l|l|l|l|}
\hline & & $\begin{array}{l}\text { system } \\
\text { dengan } \\
\text { memasukan } \\
\text { username } \\
\text { dan } \\
\text { password }\end{array}$ & & \\
\hline 2 & $\begin{array}{l}\text { Cek } \\
\text { Menu }\end{array}$ & $\begin{array}{l}\text { User } \\
\text { melakukan } \\
\text { klik menu } \\
\text { pada } \\
\text { halaman } \\
\text { utama }\end{array}$ & $\begin{array}{l}\text { User dapat } \\
\text { berpindah } \\
\text { halaman }\end{array}$ & $\begin{array}{l}\text { Sesuai } \\
\text { dengan } \\
\text { harapan } \\
\text { Valid }\end{array}$ \\
\hline 3. & Laporan & $\begin{array}{l}\text { User } \\
\text { melakukan } \\
\text { menu } \\
\text { laporan dan } \\
\text { download } \\
\text { laporan }\end{array}$ & $\begin{array}{l}\text { User dapat } \\
\text { menerima } \\
\text { laporan } \\
\text { berupa file } \\
\text { pdf }\end{array}$ & $\begin{array}{l}\text { Sesuai } \\
\text { dengan } \\
\text { harapan } \\
\text { Valid }\end{array}$ \\
\hline
\end{tabular}

\section{Pengujian White Box}

Pengujian white box merupakan sebuah pengujian yang dilakukan dengan melihat kedalam modul dan kode-kode yang ada didalam aplikasi. Tujuannya adalah sebagai petunjuk untuk mendapatkan program yang benar secara menyeluruh sehingga sistem yang dirancang mampu menghasilkan interface dan output yang sesuai dengan kebutuhan. Secara sekilas dapat diambil kesimpulan white box testing merupakan petunjuk untuk mendapatkan program yang benar secara $100 \%$.

Pengujian White Box Testing dapat dilakukan sebagai berikut :

a. $\mathrm{V}(\mathrm{G})=\mathrm{E}-\mathrm{N}+2$ hasilnya sama dengan $\mathrm{V}(\mathrm{G})=$ $\mathrm{P}+1$

b. Flowgraph mempunyai region yang sama dengan jumlah $V(G)$ maka sistem dikatakan sudah terbukti efektif dan efisien.

\section{KESIMPULAN}

Berdasarkan hasil implementasi dan pembahasan yang telah dilakukan, maka dapat ditarik kesimpulan sebagai berikut.

1. Dengan adanya system informasi Judul dan Pembimbing Skripsi/Tugas Akhir, dapat Mempermudah Staf Tata Usaha dalam membuat SK Judul dan pembimbing skripsi.

2. Sistem Informasi ini membantu user(mahasiswa/doswn) untuk melihat judul dan nama pembimbing yang sudah di SK kan secara realtime.

3. Aplikasi ini mudah diakses Karena dibuat dengan Bahasa pemrograman berbasis web..

\section{SARAN}

1. Dibutuhkan pengembangan aplikasi dalam hal akses dengan dibuatkan dengan aplikasi berbasis android.
2. Melakukan penyuluhan untuk pengembangan sumberdaya manusia yang lebih mengerti pentingnya system informasi ini bagi kampus dan individu.

3. Pengembangan selanjutnya untuk Modul aplikasi Semprop, SHP, dan Sidang untuk melengkapi modul Sistem Informasi Judul yang sudah dibuat

\section{DAFTAR PUSTAKA}

Al Fatta, Hanif. Analisis dan Perancangan Sistem Informasi untuk keunggulan bersaing Perusahaan dan Organisasi Modern. Yogyakarta : CV Andi Offset, (2007)

Coad, Peter and Yourdon, Edward. Object-Oriented Design Second Edition, Yourdon Press. 1991.

Fatansyah, Ir. (2007)."Basis Data". Bandung: Informatika Bandung.

Fowler, Martin.UML Distiled: Panduan Singkat Bahasa Pemodelan Object Standar, Edisi 3, Penerbit Andi: Yogyakarta. 2004.

Hartono, Jogiyanto. 1999. Analisis Dan Disain Sistem Informasi: pendekatan terstruktur teori dan praktek aplikasi bisnis.

http://kbbi.web.id/skripsi (Diakses Tanggal 25 Pebruari 2017)

Jogiyanto (1999:12), http://id.scribd.com/doc/49684144/16/APengertian-Aplikasi, 29 Januari 2016.

Kruchten, Philippe, The Rational Unified Process An Introduction, Second Edition, John Wiley and Son Ltd. 2006.

Nugroho Adi.Rekayasa Perangkat Lunak Berorientasi Objek dengan metode USDP (Unified Software Development Process),Penerbit Andi:Yogyakarta. 2010.

Pedoman Penyusunan Skripsi \& Tugas Akhir Fkom Uniku 2011

Pressman, Roger S. (2007). Rekayasa Perangkat Lunak: pendekatan praktisi (Buku1). Beizer, B. (1995). Black-Box Testing, Wiley. Yogyakarta: Andi 


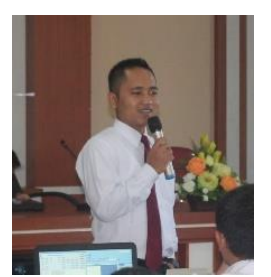

Biodata Penulis

Rio Andriyat Krisdiawan, M.Kom, memperoleh gelar sarjana di Universitas Kuningan (S.Kom) Jurusan Teknik Informatika pada tahun 2011. Dan memperoleh gelar Magister Komputer (M.Kom) dari STIMIK LIKMI Bandung pada tahun 2013. Saat ini menjadi Dosen di Universitas Kuningan Jawa Barat. Jurusan Teknik Informatika Fakultas Ilmu Komputer di Universitas Kuningan. Matakuliah yang pernah di ampu yaitu : Pemrograman WEB1, Pemrograman WEB2, Bahasa Pemrograman JAVA, Pemrograman Aplikasi Bergersan, Pemrograman Game, dan Simulasi Komputer dan Game. 